\section{Michigan Technological 1885 University}

Michigan Technological University Digital Commons @ Michigan Tech

\title{
Improved Parametric Empirical Determination of Module Short Circuit Current for Modelling and Optimization of Solar Photovoltaic Systems
}

Rob W. Andrews

Queen's University - Kingston, Ontario

Andrew Pollard

Queen's University - Kingston, Ontario

Joshua M. Pearce

Michigan Technological University

Follow this and additional works at: https://digitalcommons.mtu.edu/materials_fp

\section{Recommended Citation}

Andrews, R. W., Pollard, A., \& Pearce, Joshua M. (2012). Improved parametric empirical determination of module short circuit current for modelling and optimization of solar photovoltaic systems. Solar Energy, 86(9), 2240-2254. http://digitalcommons.mtu.edu/materials_fp/25 


\title{
Improved parametric empirical determination of module short circuit current for modelling and optimization of solar photovoltaic systems
}

\author{
Rob Andrews ${ }^{\mathrm{a}}$, Andrew Pollard ${ }^{\mathrm{a}}$, Joshua M. Pearce ${ }^{\mathrm{b}, *}$ \\ ${ }^{a}$ Department of Mechanical and Materials Engineering, Queen's University, Canada \\ ${ }^{b}$ Department of Materials Science and Engineering and Department of Electrical and Computer Engineering, Michigan Technological \\ University, USA
}

\begin{abstract}
Correct modelling of solar photovoltaic (PV) system yields is necessary to optimize system design, improve reliability of projected outputs to ensure favourable project financing and to facilitate proper operations and maintenance. An improved methodology for fine resolution modelling of PV systems is presented using module short-circuit current $\left(I_{s c}\right)$ at 5-minute time-scales, and clearly identifies pertinent error mechanisms that arise when working at this high resolution. This work used a modified version of the Sandia array performance model, and introduces new factors to the calculation of $I_{s c}$ to account for identified error mechanisms, including instrumentation alignment, spectral, and module power tolerance errors. A simple methodology was introduced and verified where specific module parameters can be derived solely from properly filtered performance time series data. In particular, this paper focused on methodologies for determining the predicted $I_{s c}$ for a variety of solar PV module types. These methods of regressive analysis significantly reduced the error of the predicted model, and demonstrate the need for this form of modelling when evaluating long term PV array performance. This methodology has applications for current systems operators, which will enable the extraction of useful module parameters from existing data in addition to more precise continuous monitoring of existing systems, and can also be used to more accurately model and optimize new systems.
\end{abstract}

Keywords: Photovoltaic, PV, System modelling, Short-circuit current, Translation models

\section{Nomenclature}

$\begin{array}{ll}G_{t} & \text { Solar irradiation }\left(W / m^{2}\right) \\ B_{t} & \text { Beam Irradiation }\left(W / m^{2}\right) \\ D_{t} & \text { Diffuse Irradiation }\left(W / m^{2}\right) \\ A_{t} & \text { Albedo Irradiation }\left(W / m^{2}\right) \\ P_{1} \ldots P_{4} & \text { Empirically derived parameters } \\ T_{m} & \text { Module Temperature }\left({ }^{\circ} \mathrm{C}\right) \\ W S & \text { Wind speed }(\mathrm{m} / \mathrm{s}) \\ \hat{I}_{s c} & \text { Modelled Short-Circuit Current }(A) \\ A M & \text { Air Mass } \\ K_{t} & \text { Clearness Ratio } \\ I_{s c} & \text { Short Circuit Current }(A) \\ I_{s c_{o}} & \text { Rated short circuit current at STC }(A) \\ G_{o} & \text { Irradiation at STC }\left(1000 W / m^{2}\right) \\ \alpha & \text { temperature coefficient }\left(1 /{ }^{\circ} C\right) \\ T_{c} & \text { module cell temperature }\left({ }^{\circ} C\right) \\ T_{o} & \text { module temperature at } \mathrm{STC}\left(25^{\circ} C\right) \\ \overline{n s} & \text { Pyranometer unit vector in the north-south plane } \\ \psi & \text { Pyranometer angle in the north-south plane }\left(^{\circ}\right) \\ \bar{e} w & \text { Pyranometer unit vector in the east-west plane } \\ \kappa & \text { Pyranometer angle in the east-west plane }\left(^{\circ}\right) \\ \gamma & \text { Azimuth angle }\left({ }^{\circ}\right) \\ \theta_{z} & \text { Zenith Angle }\left({ }^{\circ}\right) \\ G_{b} & \text { Correction factor for pyranometer plane tilt }\end{array}$

\footnotetext{
*1400 Townsend Drive Houghton, MI 49931-1295 906-487-1466 Email address: pearce@mtu.edu (Joshua M. Pearce)
}

\section{Introduction}

As the solar photovoltaic (PV) industry matures, the levelized cost of solar electricity will reach grid parity in a growing number of geographic locations (Branker et al., 2011). Critical to the development of the industry is the correct modelling of the performance of the PV system which is essential for:

(i) proper optimization of system parameters (Mondol et al., 2007; Notton et al., 2010; Al-Karaghouli and Kazmerski, 2010; Kaldellis et al., 2009)

(ii) increased reliability of the projected outputs,so as to ensure favourable project financing (Ren et al., 2009; Mondol et al., 2009) and,

(iii) proper operation and maintenance of existing systems (Stein, 2011)

The modelling of a PV system in the context of this paper will refer to the determination of the transfer function between meteorological parameters and the output form an actual PV module. In particular, this paper focuses on methodologies for determining the predicted short-circuit current $\left(I_{s c}\right)$ for a variety of module types, which can then be applied for the optimization of a system located anywhere with known meteorological data and used in the improvement and 
development of future more detailed studies. There are many available modelling routines, which have a wide range of applicability for daily, weekly or monthly time-scales, as will be described below (King et al., 2004b; Kroposki et al., 1996; Whitaker et al., 1997; De Soto et al., 2006; Kurokawa et al., 1998). Generally, as the time-scale of simulation increases, instantaneous errors due to atmospheric effects (partial or full soiling, cloud cover, aerosols, spectral shift, etc.) may be assumed to be reduced due to long term averaging, and are therefore will not be directly included. (King et al., 2004a; Whitaker and Newmiller, 1998). However, analysis of PV performance at smaller time-scales is desirable in order to identify loss mechanisms and quantify system performance on a continuous basis; therefore, the purpose of this paper is to investigate the applicability of modelling techniques with temporal resolution down to a 5-minute time-scale. To achieve this level of granularity, a more rigorous treatment of a variety of second order loss mechanisms is required as the assumption of correction through averaging is no longer valid. The purpose of increasing the granularity of the simulation is to account for all predictable mechanisms from a series of PV data. The resultant data set can be then used to quantify:

(i) system relative performance and realistic output ratios

(ii) instantaneous system output for grid integration and smart grid operation

(iii) persistent and instantaneous loss mechanisms (eg. soiling, string outages)

(iv) site specific shading losses

(v) module degradation, including both crystalline silicon (c-Si) long term degradation (Skoczek et al., 2009; A, 2003; Chianese et al., 2003) and the Staebler-Wronski effect (SWE) for amorphous silicon (Staebler and Wronski, 1977; Pearce et al., 2003; Wronski et al., 2004)

(vi) other external factors (e.g. winter albedo increases or snow losses (Andrews and Pearce, 2012a,b))

In addition, many current modelling techniques require laboratory evaluation for proper determination of modelling parameters, notably the NREL Module Energy Rating (MER) procedure (Marion et al., 1999) and the Sandia PV performance model (King et al., 2004a). The proposed technique will enable the derivation of system parameters using only a training set of system current output that is correlated with basic meteorological information, as is available from many commercial installations. The general procedure then optimizes a parametric model based on this training set, which will yield important system characteristics, and to then extrapolate these results to the entire dataset for system characterization.
The goals of this paper are to present an improved methodology for characterizing PV systems, and to demonstrate the application of this model on collected data from an outdoors testing facility. This methodology will then be compared to other leading modelling techniques applied to this dataset to demonstrate the utility of this new model. This improved modelling technique can be utilized to better optimize system parameters and predict yields, however the application of this methodology to the direct optimization of a new PV system is left for future work.

\section{Background}

A complete PV system includes solar modules, inverters, power conditioning hardware, mounting systems, and other components that are required to transform solar irradiation into grid-interactive electricity. Existing models that describe these systems will be discussed along with common sources of errors in these models.

\subsection{Previously Developed models}

Current techniques to model short-circuit current can be placed into the following main categories (i)direct transfer function (ii) empirical Tables (iii) analytical lumped diode, (iv)empirical models, (v) translation models and (vi) sophisticated validation.

\subsubsection{Direct Transfer Functions}

Direct transfer function models apply a linear transfer function for solar irradiation to determine the power output of a module, assuming constant or temperature dependant module efficiencies (Makrides et al., 2011; Whitaker and Newmiller, 1998). These models are generally used on large time-scale data, but can display a significant seasonal bias (Makrides et al., 2011). The assumption made, however, is that the errors inherent in the measurement of the input parameters to the model, other than irradiation, could be greater than the magnitude of their contribution to the model, and are thus ignored (Whitaker and Newmiller, 1998).

\subsubsection{Empirical Tables}

Empirical table models utilize a database of current-voltage $(\mathrm{I}-\mathrm{V})$ cell characteristics obtained at a variety of irradiances and temperatures. The actual performance of the modules is determined from a linear interpolation between the measured values, based on supplied meteorological conditions; however, look-up tables do not necessarily incorporate other environmental factors. That is, a fundamental assumption that is often made is that the climate and spectral conditions remain constant between the area where the testing was performed and the actual PV installation (Ransome, 2010). 


\subsubsection{Analytical Lumped Diode}

The analytical lumped diode models are based primarily on an analytical analysis of the $\mathrm{PV}$ device itself, where the module is considered as either a single or dual diode linked with a series and shunt resistance. Parameters to define the analytical circuit are then derived from cell I-V curves or from empirical or analytical relations based on information provided by a manufacturer (Akbaba and Alattawi, 1995; Xiao et al., 2004; Mermoud and Lejeune, 2010; King et al., 1996). These models take into account the basic operation of a PV cell and have been found to be highly accurate (Makrides et al., 2011). The one-diode version of the lumped-diode model is the power model that is utilized by the commercial simulation package, PVSYST, which is widely used in industry (Mermoud and Lejeune, 2010). Another notable implementation of this model is that adopted by the California Energy Commission/University of Wisconsin (De Soto et al., 2006). These models depend on the light current $\left(I_{L}\right)$, which is obtained similarly to $I_{s c}$ using:

$$
I_{L}=\frac{G_{t}}{G_{o}} f(A M) I_{s c o}\left[1+\alpha\left(G_{t}\right) T_{c}-\alpha\left(G_{o}\right) T_{o}\right]
$$

where $G_{t}$ is the global solar irradiation, $G_{o}$ is irradiation at standard testing conditions (STC), $f(A M)$ is a function that accounts for the spectral effect of air mass, $I_{s c o}$ is the module short circuit current at STC, $\alpha$ is the temperature coefficient in $1 /{ }^{\circ} C$, and $T_{c}$ and $T_{o}$ are the temperatures of the cell and STC, respectively. In some cases $I_{L}$ is presumed to be nearly directly proportional to solar irradiation (De Soto et al., 2006). Therefore, the proposed modifications to determine $I_{s c}$, as noted below can also be applied to the determination of $I_{L}$ for diode models.

\subsubsection{Empirical Models}

Empirical modelling relies on fits to meteorological data, which employ empirical parametric equations that can include information about various meteorological and performance factors. One of the most common models of this form is the one proposed by PVUSA (Whitaker et al., 1997), which is expressed as:

$$
P=G_{t}\left(P_{1}+P_{2} \cdot G_{t}+P_{3} \cdot T_{m}+P_{4} \cdot W S\right)
$$

where $P$ is the module power, $T_{m}$ is the module temperature, $W S$ is the wind speed, and $P_{1} \ldots P_{4}$ are parametric coefficients. This enables performance data to be fit to a model; however, it does not include information on spectra or long term performance degradation of the modules, and is not related to the fundamental physics affecting the models, all of which means it is difficult to apply across a wide range of meteorological conditions.

\subsubsection{Translation Models}

Translation models are used to translate PV performance information from STC to the actual operating conditions, and a standard for this translation is provided by ASTM under E1036. There are two notable practical implementations of translation models in PV system modelling adopted by NREL (Marion et al., 1999) and SANDIA (King et al., 2004b). Both these models require computation of $\hat{I_{s c}}$, the short modelled circuit current of the module, which maintain a similar form to the ASTM E1036 standard for determination of $\hat{I_{S c}}$ as given by:

$$
\hat{I_{s c}}=\frac{G_{t}}{G_{o}} I_{s c_{o}}\left[1+\alpha\left(G_{t}\right) T_{c}-\alpha\left(G_{o}\right) T_{o}\right]
$$

where the assumption is made that $\alpha$ is a function of irradiation. Both the NREL and Sandia models, assume this coefficient to be a constant function of irradiation, and the equations for the NREL and Sandia model are given as equation 4 and 5 , respectively.

$$
\begin{gathered}
\hat{I}_{s c}=I_{s c o} \frac{G_{t}}{G_{o}}\left[1+\alpha\left(T_{m}-T_{o}\right)\right] \\
\hat{I}_{s c}=I_{s c o} f(A M) \frac{B_{t} * f(A O I)+D_{t}}{G_{o}}\left[1+\alpha\left(T_{\text {module }}-T_{o}\right)\right]
\end{gathered}
$$

where $\hat{I_{s c}}$ is the modelled short circuit current, $B_{t}$ and $D_{t}$ are the beam and diffuse irradiation, respectively, and $f(A O I)$ is a function to account for reflectivity losses.

These translational models introduce a level of flexibility to include loss mechanisms in cell characterization that include temperature, spectral, solar angle of incidence, soiling, etc. This paper adopts and modifies this modelling approach.

\subsubsection{Sophisticated Validation}

Sophisticated validation, as developed by the Tokyo University of Agriculture and Technology does not directly predict module performance, but is included so as to aid in the identification of loss mechanisms that can be used for future modelling work (Matsukawa et al., 2003). The parameters include array temperature, shading, load matching, incident angle, DC circuit, "other", and "unknown" (Kurokawa et al., 1998; Oozeki et al., 2006). In particular, sophisticated validation includes a novel way to determine the shading factors on modules, which is similar to the analysis presented in this paper. The model does not, however, monitor spectral, soiling, or other atmospheric effects.

\subsection{Modelling errors}

Inherent in the models described above are errors associated with them, as noted previously: (Ransome, 2010; Makrides et al., 2011; Kroposki et al., 2000a,b; Cameron et al., 2008; Becker et al., 2008). Generally, model error is characterized by the Mean Bias Error 
(MBE) and the Root Mean Squared Error (RMSE) as these parameters provide a measure of first and second order effects (mean and its variability), respectively. Clearly, the longer the period of time over which data are collected and averaged, the mean and RMS errors should diminish.

There are issues with the modelling paradigm of long term averaging, which can be characterized generally by the loss of data resolution that could lead to poor design and operations decisions. Consider, for example, the case of a system installed in a northern climate at a large (greater than $40^{\circ}$ ) installation angle. A winter monthly average might show that the module output is as expected over this period, however this analysis neglects the fact that there is a loss of energy when the module is covered with snow, which is offset by the larger albedo present in the snow covered surroundings. In this case there is additional irradiation available from the environment that could be converted to electricity, however this would not be apparent from long term averaged data (Andrews and Pearce, 2012a). In addition, it has been shown that hourly averaging of solar irradiation data can tend to bias the level of actual irradiation towards lower values (Ransome and Funtan, 2005), leading to systemic under estimation of module performance. A review of the atmospheric and systematic effects that become more acute at smaller averaging intervals, and when accumulated can lead to long-term averaging error are discussed below.

\subsubsection{Stochastic Atmospheric effects}

Generally speaking, the measurement of solar irradiation and PV devices are not co-located. At the local test site used for this study, even modules within a $10 \mathrm{~m}$ radius of the measurement pyranometer did not display a response that could be directly correlated to the measured irradiation on a day with some cloud cover at a 5-minute time-scale, and a full description of this is given in section 4.3. Because the optical thickness of clouds is not continuous and can be considered to be random (Marshak et al., 1995), it can be seen that the amount of light incident on geographically disparate areas can vary stochastically. Therefore, the RMSE of a model will tend to increase as averaging time scale is decreased and as geographic distance between measured data locations increases.

\subsubsection{Deterministic Atmospheric effects}

Deterministic atmospheric effects relate to the attenuation of solar irradiation through atmospheric constituents, which affects both the magnitude and spectral distribution of the irradiation. The magnitude of solar irradiation is generally well understood from ground based integrating pyranometers. However, the spectral distribution of the atmospheric irradiation varies throughout the day, and broadly speaking is defined by two opposing deterministic trends: (1) the spectral distribution of the light shifts toward the infared as Air Mass (AM) increases, and (2) the spectral distribution of the light shifts toward the ultraviolet as the cloud optical thickness increases (Gottschalg, 2003). The effect of this spectral shift on PV device performance depends on the spectral response of a given technology and the tilt angle of the module (Simon and Meyer, 2011; Gottschalg et al., 2004), however the spectral shift can be determined from a convolution of the module's spectral response to the in-plane incident spectrum of light, similar to the procedure described in (Andrews and Pearce, 2012a). This work will rely upon empirical relations of atmosphere as described by AM, clearness ratio $\left(k_{t}\right)$, and beam ratio $(b)$ to module response since most sites do not have spectral data immediately available. Although, an open source spectral project that decreases the costs of these measurements considerably has been implemented (Romero et al., 2012). In addition, the recommended empirical relations only require beam and diffuse irradiation data as inputs.

\subsubsection{Module power tolerances}

Power tolerances on modules relate to the accuracy of module STC (AM1.5G, $1000 \mathrm{~W} / \mathrm{m}^{2}, T_{c} 25^{\circ}$ ) power ratings, and generally are in the range of $\pm 3 \%- \pm 5 \%$ of rated power output, depending on the manufacturer. Recent studies by (Thevenard et al., 2010) and (Poissant, 2009) also found that a majority of commercially available modules on the market operated outside their power tolerances. Because the STC rating of a module is one of the main inputs to any modelling methodology, an error in power tolerance directly translates into modelling output errors. Therefore it is desirable to include a methodology to correct for the actual power tolerance of the modules in a modelling algorithm.

\subsubsection{Module and instrumentation mis-alignment}

Accurate knowledge of the alignment of both the module and measurement instruments is required, especially if horizontal irradiation measurements are to be utilized. On long time scales, instantaneous errors due to slight misalignments will be inconsequential; however, if high resolution modelling is required, then the angles should be known precisely in order to avoid a daily fluctuating bias, and this effect was observed in the course of data analysis. In addition, the averaging interval of data collection can bias the magnitude of collected irradiation data such that a longer averaging interval will tend to artificially lower the measured magnitude of irradiation (Ransome and Funtan, 2005).

\subsubsection{Albedo irradiation}

Albedo irradiation can have a substantial effect on the total energy balance of a module (Ineichen et al., 1987; Andrews and Pearce, 2012a); however, it is not always explicitly included in many modelling methodologies, which can introduce a seasonal bias. 


\section{Methodology}

In order to adapt current modelling approaches to estimate module $I_{s c}$ at short (5-minute) time-scales, the following approach is proposed, which is an adaptation of the Sandia translation modelling approach, that follows the translation equation(5) (King et al., 2004a):

$$
\begin{aligned}
\hat{I}_{s c}= & \frac{\left(B_{t} * f(A O I) * f(A M)+D_{t} * f\left(K_{t}\right)+A_{t}\right)}{1000} \ldots \\
& \ldots I_{s c o} \phi_{I s c o}\left[1+\alpha\left(T_{c}-T_{o}\right)\right]
\end{aligned}
$$

This equation adds an albedo irradiation term $A_{t}$, a module power tolerance modifier, $\phi_{I s c o}$, an air mass spectral function, $f(A M)$ and a clearness ratio spectral function, $f\left(K_{t}\right)$. The addition of these terms enables the direct estimation of the aforementioned loss mechanisms, which were not included in equation (5).

In order to solve this equation, the independent meteorological variables must be first accurately collected with high temporal resolution. Following this, a set of module performance data is required to enable the determination of the model coefficients. Recall that the purpose of modelling is to provide the ability to predict current and future system performance both for known and future installations. The goal of this methodology is to account for the fundamental physical processes that affect PV performance, therefore improving its validity for geographically disparate systems over exiting techniques. Thus the application of the methodology permits either continual monitoring of an existing installation, or characterization of an existing system for use in the prediction of a planned installation.

\subsection{Irradiation Components}

The in-plane irradiation can be evaluated from horizontal pyranometer data, and as is common the discussion will be limited to data collected from this device. True in-plane measurements of the irradiation components are the most accurate, however care is required to account for the effects of tilt on the performance of many pyranometers (Nast, 1983). Global and diffuse irradiation can be measured using an unshaded and shaded pyranometer respectively, however, it is possible to derive diffuse irradiation from only global irradiation using a variety of methodologies ( $\mathrm{Li}$ et al., 2011; Ruiz-Arias et al., 2010; Torres et al., 2010); but it should be noted that there can be large errors associated with these techniques.

The in-plane diffuse irradiation can be calculated by a variety of approaches; the one chosen for this study is that of (Perez et al., 1990).

Because of the high temporal resolution of irradiation data, slight pyranometer tilt errors in the east-west plane imposed false daily variations in irradiation distribution.
A series of vector equations were adapted from (Boers et al., 1998) to allow for correction of irradiation values due to small errors in pyranometer level, and are summarized below:

$$
\begin{aligned}
& \overline{n s}=\left[\begin{array}{lll}
\cos (\psi) & 0 & \sin (\psi)
\end{array}\right] \\
& e \bar{w}=\left[\begin{array}{ll}
0 & \cos (\kappa) \\
\sin (\kappa)
\end{array}\right] \\
& \bar{n}=(\bar{n} s) X(e \bar{w}) \\
& \bar{s}=\left[\sin \left(\theta_{z}\right) \cos (\gamma) \sin \left(\theta_{z}\right) \sin (\gamma) \sin \left(\theta_{z}\right)\right] \\
& G_{b}=\frac{\bar{n} \cdot \bar{s}}{\left[\begin{array}{lll}
0 & 0 & 1
\end{array}\right] \cdot \bar{s}}
\end{aligned}
$$

Vectors $\overline{n s}$ and $e \bar{w}$ define a unit vector in the north-south and east-west orientations, derived from the tilt angle of the pyranometer along these directions, $\psi$ and $\kappa$ respectively. The cross product of these two vectors defines the normal to the plane of the pyranometer, $\bar{n}$. The vector representing the position of the sun is defined as $\bar{s}$. Using these vectors, the angle between the solar vector and the pyranometer normal can be computed, and compared to the angle between the solar angle and a theoretical flat plane defined by the normal vector $\left[\begin{array}{lll}0 & 0 & 1\end{array}\right]$. These angles can be used to derive the correction factor, $G_{b}$ which will correct readings from a slight pyranometer misalignment to pure horizontal measurements.

The graph in Figure 1 indicates the large effects on instantaneous relative measured irradiation from small variations in pyranometer tilt.

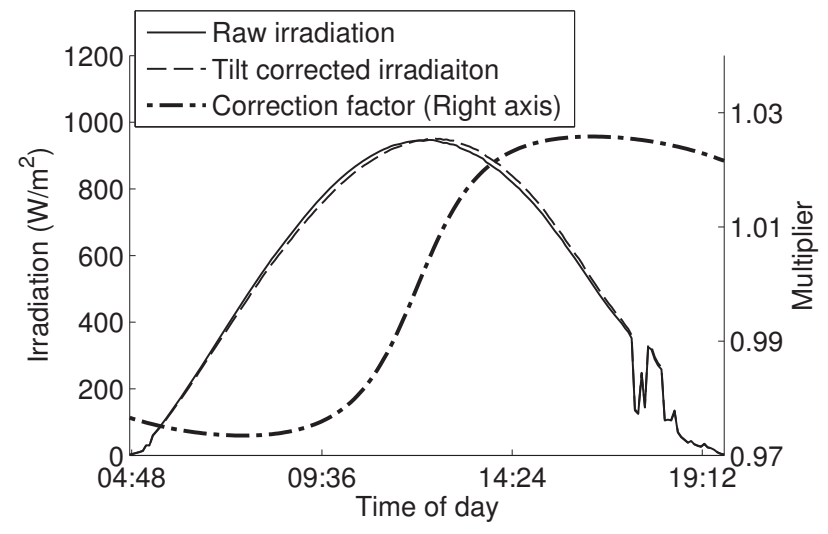

Figure 1: Effects on apparent irradiation collected due to a miss-alignment in the east-west plane of $\psi=1^{\circ}$. These small variations can lead to inaccurate predictions of Air Mass correction factors, and daily biases when used with the high resolution modelling.

\subsection{Model fitting}

The independent variables required for equation(6) are the in-plane irradiation and module temperature. The 
remainder of the coefficients in the model can be determined from empirical analysis, and the general steps for model fitting are:

(i) selection of training days of operational data,

(ii) preliminary estimation of module power tolerances,

(iii) evaluation of module temperature coefficients,

(iv) evaluation of component spectral functions, and

(v) final fitting.

\subsubsection{Determination of training days}

Training days refer to representative days of PV performance without unpredictable external influences. Generally, training days should have the following characteristics:

1. Modules are not covered or shaded, thus days where snow is present on the modules, or at zenith angles below their shading angle should be excluded. This can be determined by setting a threshold value for the module performance ratio, which for this study was set at $60 \%$.

2. Dust or soiling effects have been minimized. If there is a regular module cleaning regimen, points should be chosen at periods after the cleaning, otherwise at times when dust deposition is minimized. In this study, only days up to three days after a daily rainfall of $3 \mathrm{~mm}$ or more were included in order to attempt to minimize the effects of dust covering.

3. Nightimes and times where in-plane irradiation is less than $10 \mathrm{~W} / \mathrm{m}^{2}$ should be eliminated.

4. Points should include as wide a variety of seasons and metrological conditions as possible.

These training points should be assembled into a continuous time-series of module performance.

\subsubsection{Preliminary Estimation of $\phi_{\text {Isco }}$}

The first step in determining the remaining empirical coefficients is to reduce the bias in the model by making an estimation of the actual power tolerance of the modules being analysed. This is achieved by solving for $\hat{I}_{\text {sco }}$ using an iterative optimization of $\phi_{I s c o}$, minimizing the leastsquares objective function $(\mathrm{fcn})$ :

$$
f c n=\sum_{t=0}^{\max }\left\|\hat{I}_{s c}(t)-I_{s c}(t)\right\|^{2}
$$

with the simplified, non-spectral version of equation (6) given by:

$\hat{I}_{s c}=I_{s c o} \phi_{I s c o} \frac{\left(B_{t} * f(A O I)+D_{t}+A_{t}\right)}{1000}\left[1+\alpha\left(T_{m}-T_{o}\right)\right]$

\subsubsection{Determination of temperature coefficients}

The cell temperature can be determined from direct measurements at the back of the module or by empirical methods to determine module temperature. The cell temperature will vary from the measured module back sheet temperature and must be corrected using the relations in (King et al., 2004a).

The empirical temperature coefficient is determined by first calculating a non-spectral output ratio defined by

$$
O R=I_{s c} / \hat{I}_{s c}
$$

where $\hat{I_{s c}}$ is calculated as in equation (13). This represents the relative output of the modules as compared to the non-spectral de-biased translation model. For a properly temperature corrected module performance dataset, there should be no correlation between temperature and output ratio for constant atmospheric conditions and levels of solar irradiance. Thus, a regression dataset that contained only points in the following range was determined:

(i) $1<\mathrm{AM}<1.2$

(ii) $900<G_{t}<1000$

(iii) $\delta G_{t}<2 \mathrm{~W} / \mathrm{m}^{2} \cdot \min$

(iv) $\delta G_{t}(t-1)<2 W / m^{2} \cdot \min$

where the $\delta G_{t}$ operator returns $G_{t}(t)-G_{t}(t-1)$ and indicates the presence of fluctuating cloud cover, and the lagged operator $\delta G_{t}(t-1)$ further eliminates points that are momentarily stationary inside a period of fluctuating cloud cover. This set of parameters selects clear sky conditions in a narrow range of the clear sky spectrum, in order to reduce the effects of spectral influence on the results. Following this, a robust linear regression (Dumouchel and Fanny, 1991) of OR and cell temperature is performed, and iteratively optimized until the slope of the linear regression is equal to zero.

\subsubsection{Determination of component empirical coefficients}

The two spectral functions, $f(A M)$ and $f\left(K_{t}\right)$ were applied to the components of irradiation $\left(D_{t}, B_{t}\right)$ rather than to the global irradiation. The rationale for this is introduced in (Andrews and Pearce, 2012a), where it is noted that the spectral distribution of incident irradiation can vary significantly between beam and diffuse irradiation. The effects of AM tend to control the spectral distribution of beam irradiation, whereas cloud cover expressed as $K_{t}$ tends to control the spectral distribution of diffuse irradiation, therefore the functional dependence of these atmospheric factors is applied to the respective component of light on which they have the greatest impact.

Therefore, a beam and diffuse output ratio is defined as equations (15) and (16) respectively 


$$
\begin{gathered}
O R_{\text {Beam }}=\frac{\frac{I_{s c} * 1000}{I_{s c o} \phi_{I s c o}\left[1+\alpha *\left(T_{m}-T_{o}\right)\right]}-\left(D_{t}+A_{t}\right)}{B_{t} f(A O I)} \\
O R_{\text {Diffuse }}=\frac{\frac{I_{s c} * 1000}{I_{s c o} \phi_{I s c o}\left[1+\alpha *\left(T_{m}-T_{o}\right)\right]}-\left(B_{t}+A_{t}\right)}{D_{t}}
\end{gathered}
$$

Points representing clear sky conditions were chosen for regression of AM components, and those representing cloudy conditions were used for regression of $K_{t}$ components. In order to select these points from within the training days dataset the following criterion were utilized:

1. AM points

$$
\begin{aligned}
& \delta G_{t}(t)<6 \mathrm{~W} / \mathrm{m}^{2} \cdot \min \\
& \delta G_{t}(t-1)<6 \mathrm{~W} / \mathrm{m}^{2} \cdot \min \\
& k_{t}>.65
\end{aligned}
$$

2. $K_{t}$ points

$$
\delta G_{t}>6 \mathrm{~W} / \mathrm{m}^{2} \cdot \min
$$

A comparison of the points chosen by both sets of limits is given by Figure 2 .

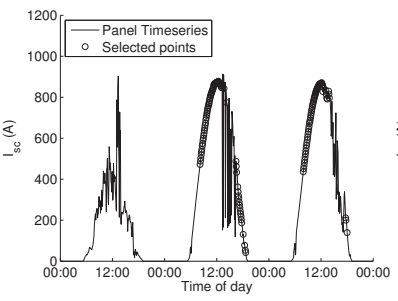

(a) Clear sky

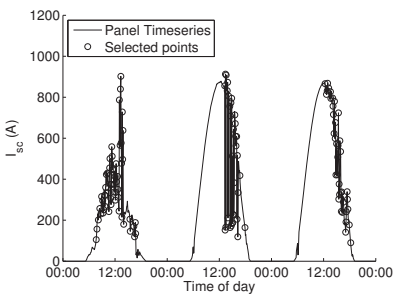

(b) Clouds
Figure 2: Example of points selected for the clear sky and cloud cases.

A regression was then performed using the beam and diffuse output ratios compared to $A M$ and $K_{t}$, respectively and the resulting trend was fit using polynomials of order two or three to formulate $f(A M)$ and $f\left(K_{t}\right)$ using robust regression methods (Dumouchel and Fanny, 1991).

\subsection{Final $\phi_{\text {Isco optimization }}$}

Once the temperature and spectral modifier functions have been determined, another least-squares optimization is performed on the full equation 6 in order to determine an appropriate value for $\phi_{\text {Isco }}$, after other predictable biases have been removed.

\section{Model Evaluation}

The proposed model was applied to a collected set of $I_{s c}$, and its relative performance was compared to other common modelling methodologies.

\subsection{Data collection}

Solar PV module performance data were collected at the Open Source Outdoors Test Field (OSOTF) located in Kingston, Ontario. This is a large scale outdoors testing site, developed in an open collaboration between 18 academic and industry partners (Pearce et al., 2012). A selected set of 20 modules at the OSOTF at tilt angle of $5^{\circ}-70^{\circ}$ were used in the analysis which encompassed both c-Si and a-Si:H PV modules. These modules are referred to by a module index, which is defined as shown in Table 1.

Table 1: Module index reference, $c$ represents crystalline and $a$ represents amorphous.

\begin{tabular}{l|ll||l|ll}
$\begin{array}{l}\text { Module } \\
\text { Index }\end{array}$ & $\begin{array}{l}\text { Module } \\
\text { Angle }\end{array}$ & $\begin{array}{l}\text { Brand } \\
\text { Identifier }\end{array}$ & $\begin{array}{l}\text { Module } \\
\text { Index }\end{array}$ & $\begin{array}{l}\text { Module } \\
\text { Angle }\end{array}$ & $\begin{array}{l}\text { Brand } \\
\text { Identifier }\end{array}$ \\
\hline \hline $1 \mathrm{c}$ & $5^{\circ}$ & 1 & $1 \mathrm{a}$ & $5^{\circ}$ & 4 \\
$2 \mathrm{c}$ & $10^{\circ}$ & 1 & $2 \mathrm{a}$ & $5^{\circ}$ & 4 \\
$3 \mathrm{c}$ & $10^{\circ}$ & 2 & $3 \mathrm{a}$ & $5^{\circ}$ & 4 \\
$4 \mathrm{c}$ & $15^{\circ}$ & 3 & $4 \mathrm{a}$ & $10^{\circ}$ & 4 \\
$5 \mathrm{c}$ & $20^{\circ}$ & 1 & $5 \mathrm{a}$ & $10^{\circ}$ & 4 \\
$6 \mathrm{c}$ & $20^{\circ}$ & 2 & $6 \mathrm{a}$ & $10^{\circ}$ & 4 \\
$7 \mathrm{c}$ & $40^{\circ}$ & 1 & $7 \mathrm{a}$ & $20^{\circ}$ & 4 \\
$8 \mathrm{c}$ & $40^{\circ}$ & 2 & $8 \mathrm{a}$ & $20^{\circ}$ & 4 \\
$9 \mathrm{c}$ & $60^{\circ}$ & 1 & $9 \mathrm{a}$ & $40^{\circ}$ & 4 \\
$10 \mathrm{c}$ & $60^{\circ}$ & 2 & $10 \mathrm{a}$ & $60^{\circ}$ & 4
\end{tabular}

The modules and meteorological conditions were monitored at 5-minute intervals, $I_{s c}$ was measured using an optically isolated current shunt circuit, and module back sheet temperature measurements were made with type $\mathrm{T}$ thermocouples with field-welded junctions. Incident irradiation was measured using two CMP-22 pyranometers, one with a shadow band measuring diffuse irradiation and one measuring global irradiation. Temperature, RH, Wind speed and direction and time-lapse photos were also recorded (Pearce et al., 2012).

Using this collected information, the methodology described in section 3 was applied to the collected performance datasets in order to identify its ability to predict module performance, and was compared to other modelling techniques.

\subsection{Modelling results}

Initially, summary graphs are shown, which demonstrate the development of model coefficients.

\subsubsection{Temperature Coefficients}

Figure 3 shows an example of a regression analysis for temperature correction for a-Si:H and c-Si PV. The regression dataset shows the temperature dependence of a narrow band of constant spectrum and irradiation data, and the full dataset shows the trends apparent in 
the total set. Because higher module temperatures tend to occur at times of lower AM, the trends in the full dataset could be showing some spectral dependence as well. Figure 4 presents the combined results of the regression analysis in determining the appropriate temperature coefficients for all amorphous silicon and crystalline silicon modules included in this study, compared to the manufacturer's datasheet value.
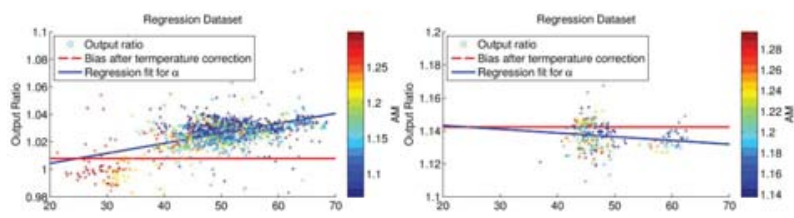

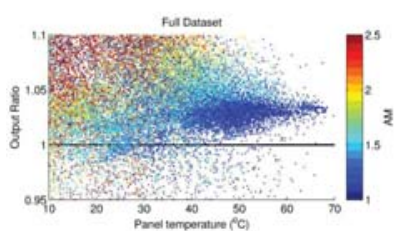

(a) Crystalline

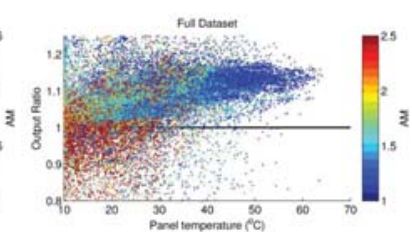

(b) Amorphous
Figure 3: Sample of a-Si:H and c-Si temperature coefficient regressions

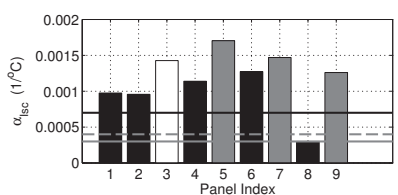

(a)

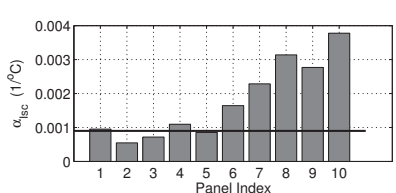

(b)
Figure 4: Resultant temperature coefficients, the horizontal lines represents the data-sheet value of $\alpha_{I S C}$ for each module. In the case of the crystalline modules, the colour of the bars matches to the data sheet line, in the case of the white bar, the matching line is the dashed grey line.

\subsubsection{Spectral coefficients}

In order to determined the spectral components, a regression analysis was performed to find a polynomial which fit the proposed data. There is some scatter inherent in this method of data regression, and it was found that the use of a robust iterative fitting algorithm produced the most reliable results. The regression analysis for $f(A M)$ was performed against the beam output ratio for a polynomial fit of order three and is shown in Figure 5 and the $f(A M)$ proposed by Sandia is shown as a thick solid line.

This regression was performed for all modules in the study and a summary of $f(A M)$ for varying module angles

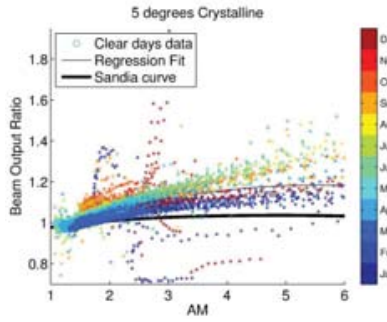

(a)

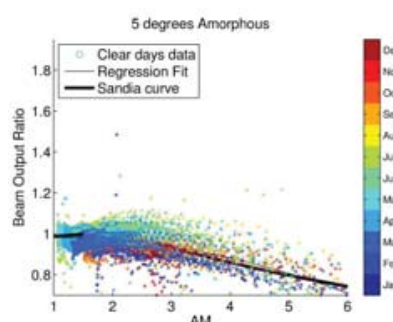

(c)

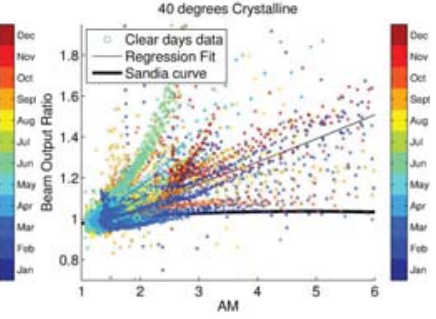

(b)
Figure 5: AM regression results, the sandia AM curve is shown for comparison (King et al., 2004a). (a) and (b) show c-Si modules at $5^{\circ}$ and $40^{\circ}$ and (b) and (c) show a-Si:H modules at $5^{\circ}$ and $40^{\circ}$

and technologies is shown in Figure 6, compared to the Sandia air mass correction factor.

Similarly, a regression is performed for $f\left(K_{t}\right)$ using a robust algorithm to find a polynomial of order two, and the regression for selected modules is shown in Figure 7. A summary of the $f\left(K_{t}\right)$ for all the modules in the study is shown in Figure 8.

\subsubsection{Module power tolerance determination}

After spectral regression, the final optimized values for $\phi_{\text {Isco }}$ were determined using a least-squares fitting algorithm. The results for all modules involved in the study is summarized in Figure 9, which indicates module tolerance variation between manufacturers.

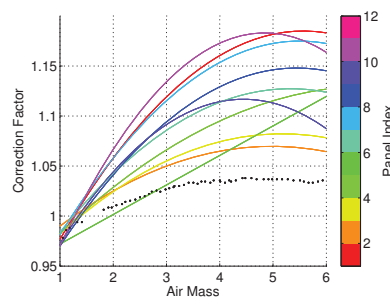

(a) Crystalline

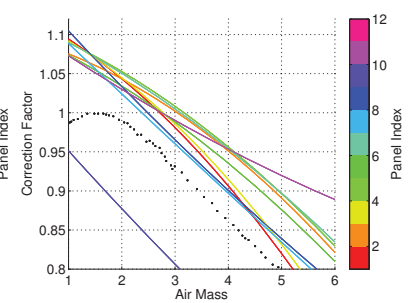

(b) Amorphous
Figure 6: (a) and (b) show a summary of $f(A M)$ for crystalline and amorphous silicon PV modules, respectively. The dotted line is the reported curve from the Sandia model (King et al., 2004a). 


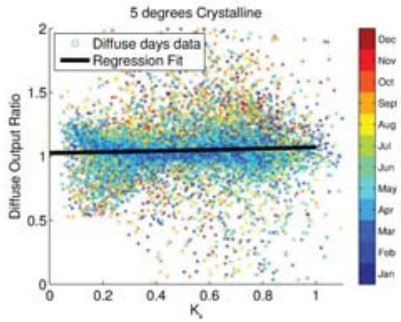

(a)

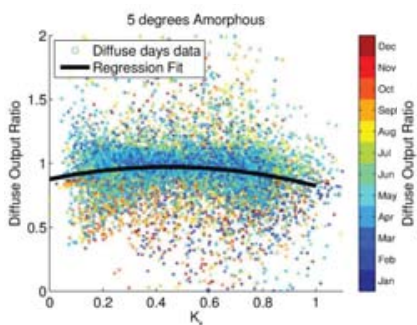

(c)

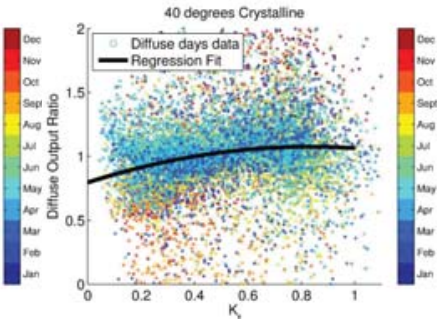

(b)

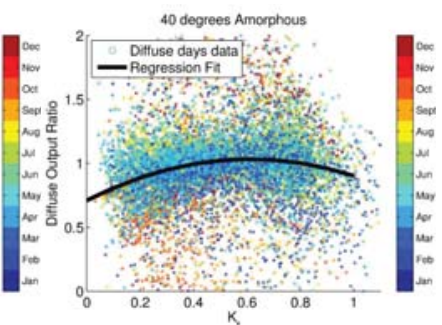

(d)
Figure 7: $\quad k_{t}$ regression results, (a) and (b) show c-Si modules at $5^{\circ}$ and $40^{\circ}$ and (b) and (c) show a-Si modules at $5^{\circ}$ and $40^{\circ}$

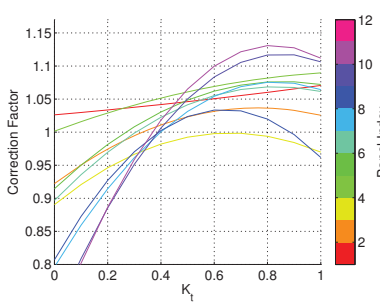

(a) Crystalline

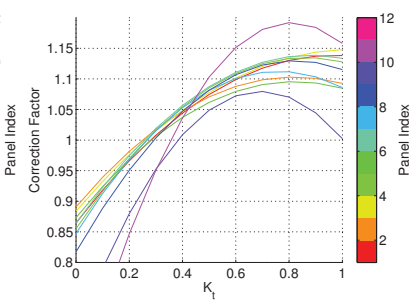

(b) Amorphous
Figure 8: $f\left(k_{t}\right)$ for crystalline (a) and amorphous silicon (b) modules.

\subsection{Model Errors}

To quantify the quality of fit of the model, the RMSE and MBE of the modified model compared to other similar methodologies are compared in Figure 10. In addition, in order to identify the seasonal stability of the prediction, a moving average representation of the model errors over the period of observation as shown in Figure 11, where averaging at a daily and weekly resolution is shown.

It can be seen that the model NRMSE is relatively large at these small time-scales. This can be explained by considering the effects of stochastically varying cloud cover. In order to demonstrate this, Figure 12 shows the autocorrelation function of the error between pyranometer output and scaled $I_{s c}$ for a module within a $10 \mathrm{~m}$ radius of the pyranometer, calculated according to the methods in (Brockwell and Davis, 2002). This figure indicates that there is not a significant correlation in

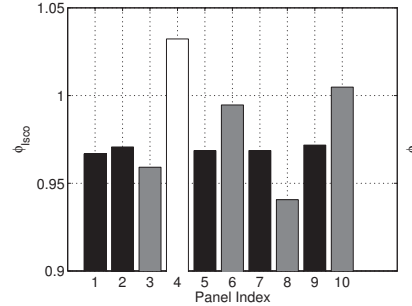

(a) Crystalline (b) Amorphous

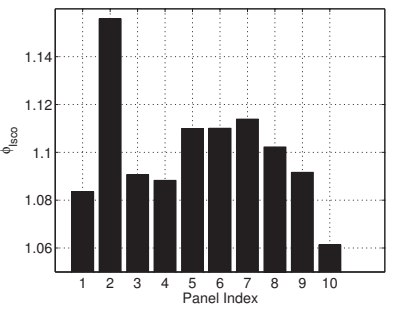

Figure 9: $\phi_{\text {Isco }}$ showing variation in power tolerances for c-Si(a) and a-Si:H (b) PV modules, the shades represent the manufacturers.

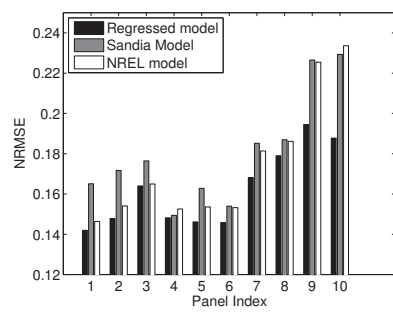

(a) Crystalline NRMSE

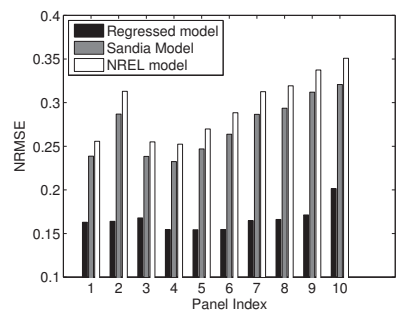

(c) Amorphous NRMSE

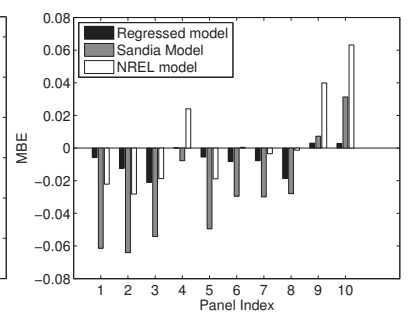

(b) Crystalline MBE

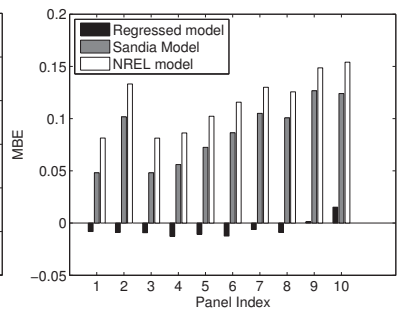

(d) Amorphous MBE
Figure 10: Quantification of model errors in terms of NRMSE for (a)c-Si and (c) a-Si:H , and of MBE for (b) c-Si and (d) a-Si:H.

time for the difference between pyranometer and module response on a day with cloud cover present, but that there is a high correlation in the absence of cloud cover. Therefore, because on a cloudy day the pyranometer and module are not subject to the same irradiation, there will be a relative error in the model which cannot be corrected, and which increases as averaging interval decreases.

\section{Discussion}

In a translation model for PV performance, the proper determination of $I_{s c}$ is the most critical, as it is directly affected by a wide variety of environmental factors. Thus, the purpose of this methodology is to improve the accuracy of prediction of $I_{s c}$, and also to enable the extraction of useful system performance information from 


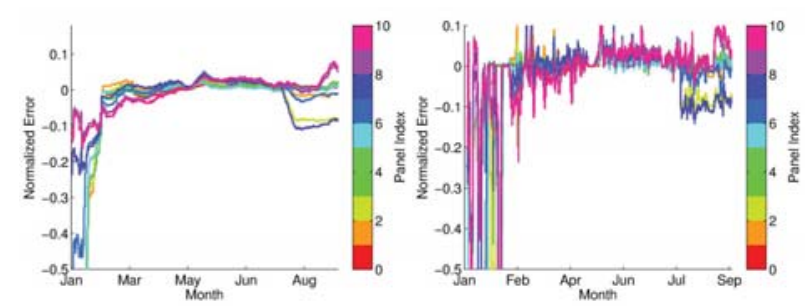

(a) Crystalline, 1 week averaging (b) Crystalline, 1 day averaging

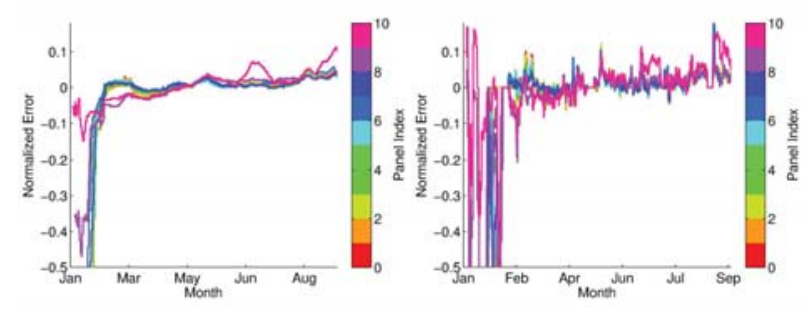

(c) Amorphous, 1 week averaging (d) Amorphous, 1 day averaging

Figure 11: Moving average representation of time series errors. (a) and (b) show weekly averaging for c-Si and a$\mathrm{Si}: \mathrm{H}$ respectively and (b) and (d) show daily averaging for c-Si and a-Si:H, respectively

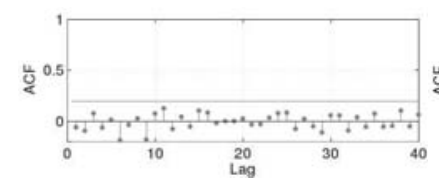

(a)

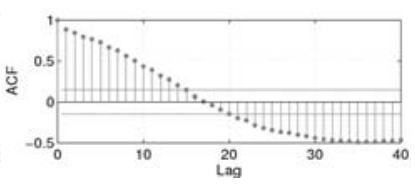

(b)
Figure 12: Autocorrelation function of the difference between pyranometer and PV module output over a day. The lag represents time into the sample, the value of the autocorrelation is proportional to the relation between points separated by a given lag. The horizontal lines represent the significance bounds for this lag. (a) Errors on a cloudy day and (b) Errors on a clear day

a collected time series of module performance. The understanding and inclusion of the underlying processes that affect $I_{s c}$ will also increase the applicability of the model to other geographic and therefore atmospheric areas. The goal of this process is to allow integration into previously developed and validated power models, such as the Sandia performance or lumped diode models.

Compared to other models, it can be seen that the proposed methodology has a lower RMSE and significantly lower MBE than both predictive models. This can be expected as the proposed model contains information measured from the system it is modelling, however it demonstrates the magnitude of errors that are possible when system data are not included in the modelling process. It was found that the largest gains in
MBE can be attributed to determination of $\phi_{I s c o}$, however, improvements are also present from the determination of system specific spectral and temperature coefficients.

\subsection{Inclusion of $f\left(K_{t}\right)$}

The inclusion of $f\left(K_{t}\right)$ can be justified by a demonstration diffuse output ratio dependence on clearness ratio for periods of high diffuse irradiation. However, because of the stochastic nature of the errors shown during diffuse modelling, there is significant scatter in these data. The physical realities of the underlying process indicate that as the clearness ratio increases, the spectrum tends to shift towards red and away from the spectral response of both devices, thus decreasing the effective irradiation on the face of the module. However, the opposite trend is seen in both module technologies. The inclusion of this factor can thus be debated, however it does enable proper system modelling especially in climates that experience high levels of diffuse irradiation, and its inclusion decreases the RMSE of the resulting model.

\subsection{Module Power tolerances}

It can be seen that it is possible to extract information related to module power tolerances from the time-series performance data. From this analysis, it can be seen that the c-Si modules ranged from under performing by $5 \%$ to over performing by $3 \%$ relative to their rated performance depending on the manufacturer. In the case of the a-Si:H based module, there is a clear trend of module performance related to module index. Because this is the first year of installation of these amorphous modules, it is likely that initial degradation due to the Staebler-Wronski effect can account for the large variability in performance over this first year.

\subsection{Moving average representation of time series data}

Figure 11 demonstrates a method of displaying seasonal bias in time series data. It can be seen that averaged over a weekly period, the normalized model error is within $5 \%$ for both models, and that there are no major seasonal trends visible in the snow free months. However, as the averaging interval is increased to a daily average, the normalized error can be seen to increase as more stochastic events increase the variance in the signals. This is important for realizing the large values of RMSE recorded for all models in this paper are due to the very small averaging interval used in the dataset, and demonstrates that over larger averaging intervals, the model error begins to approximate the bias error.

\subsection{Uses of regression modelling}

The methodologies presented here have applicability in the design and optimization of new systems; however, there is utility to be had from regression modelling of 
existing systems. Initially, it allows the determination of important system characteristics, as discussed earlier. It also allows for a detailed account of mechanisms affecting systems performance, for example the effects of snowfall on system performance can be seen in the time-series data, with larger errors existing in January, February and March at the OSOTF. Interestingly, it can be seen that c-Si modules at $60^{\circ}$, when analysed on a daily averaging interval can be seen to outperform system projections at the beginning of the year, indicating that the increased albedo from the newly fallen snow increased the incident irradiation.

Additionally, regression modelling allows for precise near-term forecasting of system production for use in grid integration and smart and micro grid development. Finally, it can be used for tracking of system health, and thus to identify cell and module failures in a system. For example, it is apparent from the dataset that modules 2 , 5 , and 7 experienced some form of failure in early August, which warranted further investigation.

\section{Conclusions}

This study has demonstrated improvements to current photovoltaic modelling methodologies, which allow for more accurate prediction of system performance at small time-scales. The results demonstrated that differences in module tolerances can have large influences on the error of resulting estimations, and that the inclusion of actual module tolerances through regressive analysis can significantly reduce this error. In addition, it was shown that specific module performance parameters can be derived solely from properly filtered performance time series data. Simple methods were introduced to filter these data, and examples of the required regressive analysis were shown. In addition, model error mechanisms were identified and addressed. This methodology has applications for current systems operators, which will enable the extraction of useful module parameters from existing data in addition to more precise continuous monitoring of existing systems, and can also be used to more accurately model and optimize new systems.

\section{Acknowledgements}

The authors would like to acknowledge work of $\mathrm{H}$. McLaren, J. Fairborn, Q. Richardson, D. Carter and A. Babasola and the support of the Sustainable Energy Applied Research Centre at St.Lawrence College in addition to support from the Natural Sciences and Engineering Research Council of Canada and a Social Sciences and Humanities Research Council Strategic Research Grant on Environmental Issues.

\section{References}

A, R., 2003. MTBF PVm, mean time before failure of photovoltaic modules, final report. Final report BBW 99.0579.

Akbaba, M., Alattawi, M.A., 1995. A new model for IV characteristic of solar cell generators and its applications. Solar Energy Materials and Solar Cells 37, 123-132.

Al-Karaghouli, A., Kazmerski, L., 2010. Optimization and life-cycle cost of health clinic PV system for a rural area in southern iraq using HOMER software. Solar Energy 84, 710-714.

Andrews, R., Pearce, J.M., 2012a. The effect of spectral albedo on amorphous silicon and crystalline silicon solar photovoltaic device performance. To be published .

Andrews, R., Pearce, J.M., 2012b. Prediction of energy effects on photovoltaic systems due to snowfall events. IEEE PVSC (To be published)

Becker, G., Schiebelserger, B., Weber, W., Schumacher, J., Zehner, M., Wortuba, G., Vodermayer, C., 2008. Energy yields of PV systems- comparison of simulation and reality., Valencia, Spain.

Boers, R., Mitchell, R.M., Krummel, P.B., 1998. Correction of aircraft pyranometer measurements for diffuse radiance and alignment errors. Journal of Geophysical Research 103, PP. $16,753-16,758$

Branker, K., Pathak, J., Pearce, J.M., 2011. A review of solar photovoltaic levelized cost of electricity. Renewable \& Sustainable Energy Reviews 15, 4470-4482.

Brockwell, P.J., Davis, R.A., 2002. Introduction to time series and forecasting. Springer.

Cameron, C.P., Boyson, W.E., Riley, D.M., 2008. Comparison of PV system Performance-Model predictions with measured PV system prediction, San Diego, CA, USA.

Chianese, D., Realini, A., Cereghetti, N., Rezzonico, A., Bura, E., Friesen, G., Bernasconi, A., 2003. Analysis of weathered c-Si PV modules, in: Proceedings of 3rd World Conference on Photovoltaic Energy Conversion, 2003, IEEE. pp. 2922-2926 Vol.3.

De Soto, W., Klein, S., Beckman, W., 2006. Improvement and validation of a model for photovoltaic array performance. Solar Energy 80, 7888.

Dumouchel, W., Fanny, O., 1991. Integrating a robust option into a multiple regression computing environment. Institute for Mathematics and Its Applications 36, 41.

Gottschalg, R., 2003. Experimental study of variations of the solar spectrum of relevance to thin film solar cells. Solar Energy Materials and Solar Cells 79, 527-537.

Gottschalg, R., Betts, T.R., Infield, D.G., Kearney, M.J., 2004. On the importance of considering the incident spectrum when measuring the outdoor performance of amorphous silicon photovoltaic devices. Measurement Science and Technology 15, 460-466.

Ineichen, P., Perez, R., Seals, R., 1987. The importance of correct albedo determination for adequately modeling energy received by tilted surfaces. Solar Energy 39, 301-305.

Kaldellis, J., Zafirakis, D., Kondili, E., 2009. Optimum autonomous stand-alone photovoltaic system design on the basis of energy payback analysis. Energy 34, 1187-1198.

King, D.L., Boyson, W., Kratochvil, J., 2004a. Photovoltaic array performance model.

King, D.L., Boyson, W.E., Kratochvil, J.A., 2004b. Photovoltaic array performance model. Sandia SAND2004-3535.

King, D.L., Dudley, J.K., Boyson, W.E., 1996. PVSIMC: a simulation program for photovoltaic cells, modules, and arrays, in: , Conference Record of the Twenty Fifth IEEE Photovoltaic Specialists Conference, 1996, IEEE. pp. 1295-1297.

Kroposki, B., Marion, W., King, D., Boyson, W., Kratochvil, J., 2000a. Comparison of Module Performace Characteriation methods fo energy production. Technical Report NREL/TP520-29245.

Kroposki, B., Marion, W., King, D.L., Boyson, W.E., Kratochvil, J.A., 2000b. Comparison of module performance characterization methods, in: Conference Record of the Twenty-Eighth IEEE Photovoltaic Specialists Conference, 2000, IEEE. pp. 1407-1411. 
Kroposki, B., Myers, D., Emery, K., Mrig, L., Whitaker, C., Newmiller, J., 1996. Photovoltaic module energy rating methodology development, in: , Conference Record of the Twenty Fifth IEEE Photovoltaic Specialists Conference, 1996, IEEE. pp. 1311-1314.

Kurokawa, K., Sugiyama, H., Uchisa, D., Sakamoto, K., Ohsiro, T., Otani, K., Fukasawa, K., 1998. Sophisticated verification of simple monitored data for japanese field test program, Vienna, Austria.

Li, H., Ma, W., Wang, X., Lian, Y., 2011. Estimating monthly average daily diffuse solar radiation with multiple predictors: A case study. Renewable Energy 36, 1944-1948.

Makrides, G., Zinsser, B., Schubert, M., Georghiou, G.E., 2011. Energy yield prediction errors and uncertainties of different photovoltaic models. Progress in Photovoltaics: Research and Applications .

Marion, B., Kroposki, B., Emery, K., del Cueto, J., Myers, D., Osterwald, C., 1999. Validation of a photovoltaic module energy ratings procedure at NREL.

Marshak, A., Davis, A., Wiscombe, W., Cahalan, R., 1995. Radiative smoothing in fractal clouds. Journal of Geophysical Research 100, 26247-26261.

Matsukawa, H., Pimentel, P.S., Izawa, T., Ike, S., Koizumi, H., Kurokawa, K., 2003. An integrated design software for photovoltaic systems, in: Proceedings of 3rd World Conference on Photovoltaic Energy Conversion, 2003, IEEE. pp. 1930-1933 Vol.2.

Mermoud, A., Lejeune, T., 2010. Performance assessment of a simulation model for PV modules of any available technology, in: 25th European PV Solar Energy Conference, Valencia.

Mondol, J.D., Yohanis, Y.G., Norton, B., 2007. The impact of array inclination and orientation on the performance of a grid-connected photovoltaic system. Renewable Energy 32, 118-140.

Mondol, J.D., Yohanis, Y.G., Norton, B., 2009. Optimising the economic viability of grid-connected photovoltaic systems. Applied Energy 86, 985-999.

Nast, P., 1983. Measurements on the accuracy of pyranometers. Solar Energy 31, 279-282.

Notton, G., Lazarov, V., Stoyanov, L., 2010. Optimal sizing of a grid-connected PV system for various PV module technologies and inclinations, inverter efficiency characteristics and locations. Renewable Energy 35, 541-554.

Oozeki, T., Otani, K., Kurokawa, K., 2006. An evaluation method for PV system to identify system losses by means of utilizing monitoring data, in: Conference Record of the 2006 IEEE 4th World Conference on Photovoltaic Energy Conversion, IEEE. pp. 2319-2322.

Pearce, J.M., Babasola, A., Andrews, R., 2012. Open solar photovoltaic systems optimization. Proceedings of the 16th Annual National Collegiate Inventors and Innovators Alliance Conference, Open 2012 .

Pearce, J.M., Deng, J., Collins, R.W., Wronski, C.R., 2003. Lightinduced defect states in hydrogenated amorphous silicon centered around 1.0 and $1.2 \mathrm{eV}$ from the conduction band edge. Applied Physics Letters 83, 3725-3727.

Perez, R., Ineichen, P., Seals, R., Michalsky, J., Stewart, R., 1990. Modeling daylight availability and irradiance components from direct and global irradiance. Solar Energy 44, 271-289.

Poissant, Y., 2009. Field assesment of novel PV module technologies in canada, in: 4th Canadian Solar Buildings Conference.

Ransome, S., 2010. Comparing PV simulation models and methods with outdoor measurements, in: Photovoltaic Specialists Conference (PVSC), 2010 35th IEEE, p. 002306002311.

Ransome, S., Funtan, P., 2005. Why hourly averaged measurement data is insufficient to model PV system performance accurately.

Ren, H., Gao, W., Ruan, Y., 2009. Economic optimization and sensitivity analysis of photovoltaic system in residential buildings. Renewable Energy 34, 883-889.

Romero, F., Urquidi, O., Ormachea, O., Abrahamse, A., Pearce, J., Andrews, R., de Vuono, M., 2012. Desarrollo de un sistema de monitoreo de radiacion solar basado en un expectrometro de amplio espectro (Development of a solar radiation monitoring system based on a wide range spectrometer). To be published

Ruiz-Arias, J., Alsamamra, H., Tovar-Pescador, J., Pozo-Vzquez, D., 2010. Proposal of a regressive model for the hourly diffuse solar radiation under all sky conditions. Energy Conversion and Management 51, 881-893.

Simon, M., Meyer, E.L., 2011. The effects of spectral evaluation of cSi modules. Progress in Photovoltaics: Research and Applications $19,1-10$.

Skoczek, A., Sample, T., Dunlop, E.D., 2009. The results of performance measurements of fieldaged crystalline silicon photovoltaic modules. Progress in Photovoltaics: Research and Applications 17, 227-240.

Staebler, D.L., Wronski, C.R., 1977. Reversible conductivity changes in discharge-produced amorphous si. Applied Physics Letters 31, 292.

Stein, J.S., 2011. Coupled performance and reliability modeling of PV systems and components: Evaluating design and O\&M strategies, Dallas, Texas.

Thevenard, D., Driesse, A., Turcotte, D., Poissant, Y. 2010. Uncertainty in Long-Term Photovoltaic Yield Predictions. Technical Report 2010-122 (RP-TEC) 411-IEARES. CanmetENERGY, Natural Resources Canada.

Torres, J., De Blas, M., Garca, A., de Francisco, A., 2010. Comparative study of various models in estimating hourly diffuse solar irradiance. Renewable Energy 35, 1325-1332.

Whitaker, C.M., Newmiller, J.D., 1998. Photovoltaic module energy rating procedure. Final subcontract report. Technical Report NREL/SR-520-23942. NREL.

Whitaker, C.M., Townsend, T.U., Newmiller, J.D., King, D.L. Boyson, W.E., Kratochvil, J.A., Collier, D.E., Osborn, D.E., 1997. Application and validation of a new PV performance characterization method, in: , Conference Record of the TwentySixth IEEE Photovoltaic Specialists Conference, 1997, IEEE. pp. 1253-1256

Wronski, C., Pearce, J., Deng, J., Vlahos, V., Collins, R., 2004 Intrinsic and light induced gap states in a-Si:H materials and solar cells? effects of microstructure. Thin Solid Films 451-452, 470-475.

Xiao, W., Dunford, W.G., Capel, A., 2004. A novel modeling method for photovoltaic cells, in: Power Electronics Specialists Conference, 2004. PESC 04. 2004 IEEE 35th Annual, IEEE. pp. $1950-1956$ Vol.3. 